\title{
Al Based Drones for Security Concerns in Smart Cities
}

\author{
Bhupesh Rawat ${ }^{1}$, Ankur Singh Bist ${ }^{2}$, Desy Apriani ${ }^{3}$, Nur Ihsan Permadi ${ }^{4}$, Efa Ayu Nabila \\ 1,2Graphic Era Hill University Bhimtal Campus \\ $3,4,5$ University of Raharja \\ ${ }^{1,2}$ Road Society Area, Oghal Bhatta, Clement Town, Dehradun, Uttarakhand 248002, India \\ 3,4,5Modern, Jl. Jenderal Sudirman No.40, Cikokol, Kec. Tangerang, Kota Tangerang, Banten \\ 15117 \\ e-mail: bhr222@gmail.com¹, ankur1990bist@gmail.com² ${ }^{2}$,desy@raharja.info ${ }^{3}$, \\ nur.ihsan@raharja.info ${ }^{4}$, efaayunabila@raharja.info ${ }^{5}$
}

To cite this document :

Rawat, B., Bist, A.S., Apriani, D., Permadi, N.I., \& Nabila, E.A. (2023) Al Based Drones for Security Concerns in Smart Cities. Aptisi Transactions on Management (ATM), 7(2), 125130.

DOI :

https://doi.org/10.33050/atm.v7i2.1834

\begin{abstract}
The concept of a smart city has attracted the attention of all corners of the world. It updated with new technologies like Al, Blockchain, IoT, Drones, and many other things. Security in big cities is one of the main concerns, and everyone wants to feel safe 24/7 in every activity they do. In this paper, our research aims to highlight the use and importance of drones for intelligent city management, especially in the context of security. The drone security management flow is explained using the methods and technical details. This is followed by discussion on security concern in cities and how it is dealt with Al based drones. In the conclusion section, it is discussed how emerging technology such as blockchain can help improve the management of smart cities. The use of drones supports the intelligent city concept with all its advantages in regional monitoring. Concept of smart cities is catching attention across the globe and it's important as per context of emerging economies. In this paper, we discussed about the use of emerging technologies to make it possible. Al, Blockchain and Drone technologies are playing important role. Their significance and attention by researchers in exploring possibilities is shown in this paper. This paper will be very useful for researchers and engineers working in the same domain.
\end{abstract}

Keywords: Smart City, Al, Blockchain, Drones

\section{Introduction}

Artificial intelligence is one of the fast emerging and widely accepted technologies in modern time. Al mimics human brain functioning to solve real life problems. Application areas of Al include robot, smart car, prediction, in e-commerce, navigation, human resource, healthcare, agriculture, gaming, automobile, social media and marketing. Security is one of the major concerns for any individual, organization and society which is being addressed with the help of artificial intelligence. Al security refers to tools and techniques that leverage artificial intelligence (AI) to autonomously identify and/or respond to potential cyber threats based on similar or previous activity[1].If we look at Al security, then it is a comprehensive area. For example, sophisticated Al algorithms are extensively used to detect malware, run pattern recognition and detect even the minutest behavior of malware even before it enters the system. With fast-evolving 
cyber attacks and rapid multiplication of devices happening today, $\mathrm{Al}$ and machine learning can help to keep abreast with cybercriminals, automate threat detection, and respond more effectively than conventional software-driven or manual techniques[2]. Al is being used for detecting cyberthreats and malicious activities in cyberworld so in this area artificial intelligence techniques can immensely help to prevent the threats. In combination with natural language processing $\mathrm{Al}$ can help to extract patterns from textual data to find any threat that can occur. Another interesting area where Al can battle with bot(a malicious program that can create bogus accounts with stolen credentials can be a real menace. In addition to previously discussed application areas of $\mathrm{Al}$, it is being widely used.

This paper is organized as follows: Firstly, we discuss the concept of smart city in the light of artificial intelligence technology and how Al based system are being used for the management of smart cities. In the next section, our focus would be on the detailed discussion on how the blockchain technology can empower smart cities. As drones are extensively used by security agencies and other organization in general for monitoring any malicious activities so our subsequent section explains how Al based drones can further enhance the surveillance of any event. This is followed by discussion on security concern in cities and how it is dealt with Al based drones. In the conclusion section, it is discussed how emerging technology such as blockchain can help improve the management of smart cities.

\section{Al for Smart Cities}

$\mathrm{Al}$ is one of the best suited technologies for smart city management. Lots of articles have been written in the same domain [3][4][5] that reflect the significance of Al for smart cities. Identity management, smart traffic, smart grid, precision farming, smart healthcare etc. are applications of Al for smart cities.

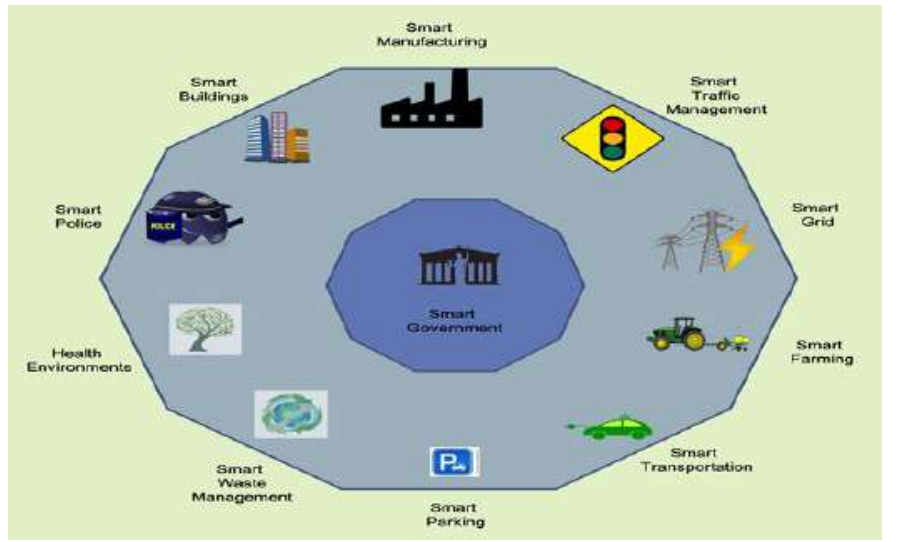

Figure1: Al applications in smart cities

\section{Block Chain for Smart Cities}

Blockchain is one of the emerging technologies for smart city. Lots of papers have been written [6][7][8] that reflects the significance of Blockchain for smart cities. Universal ID cards, Universal data storage and management, smart contract for properties etc. are application of Blockchain for smart cities. 


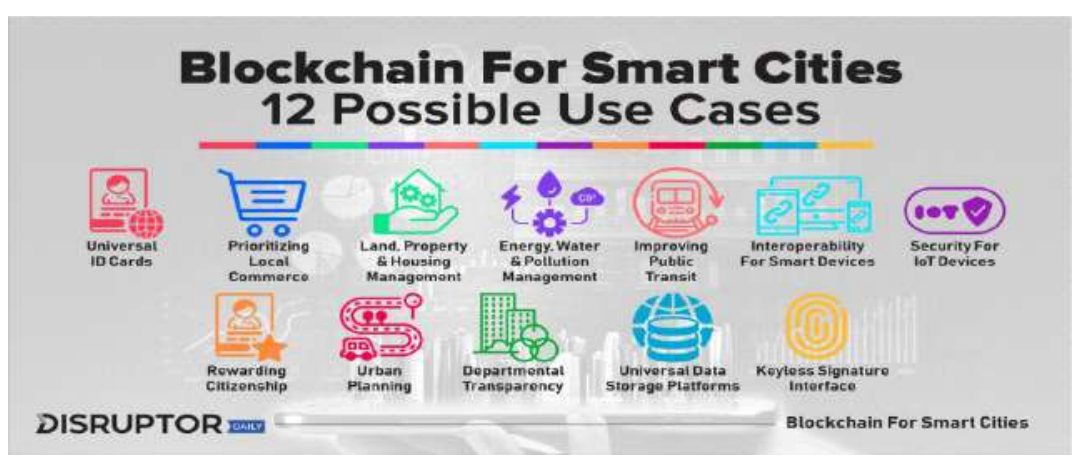

Figure 2. Blockchain applications in smart cities

Figure 2 above is an example of 12 Use Cases that can be used in smart cities. Among them can be used regarding Universal Data Storage Platforms, Keyless Signature Interfaces, Security for loT Devices, and others. With these 12 Use Cases, we can provide a future picture of how smart cities are very beneficial to society.

\section{Drones for Smart Cities}

Drone is one of the emerging technologies used in smart cities. Lots of papers have been written [9][10][11] that reflect the significance of drones for smart cities. Surveillance, traffic management, goods delivery etc. are applications of drones for smart cities.

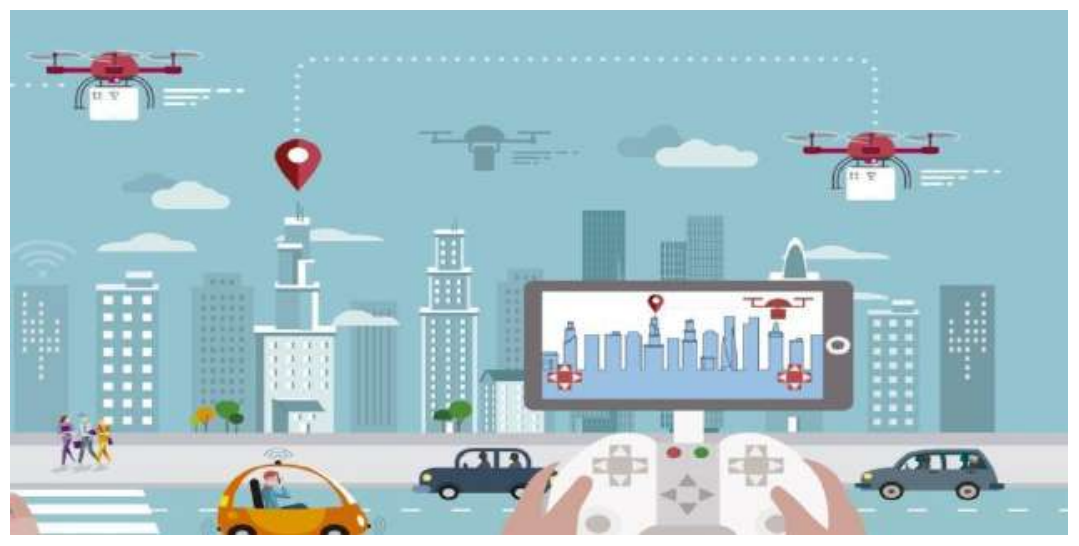

Figure 3. Drone applications in smart cities

\section{Security Concern in Cities}

Recent advancement in drone technologies present both opportunity and challenges in different areas of life as shown in figure.1. 


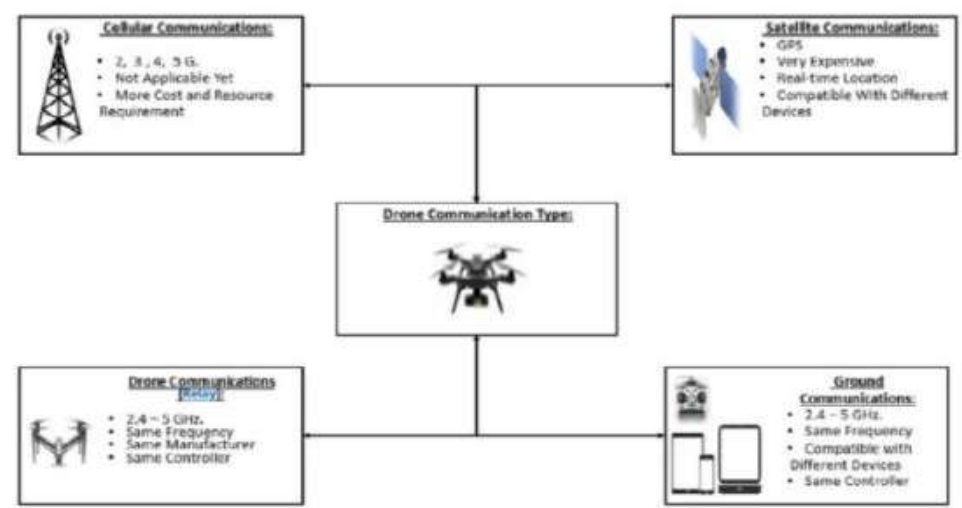

Figure 4. Drone usage in different areas of life

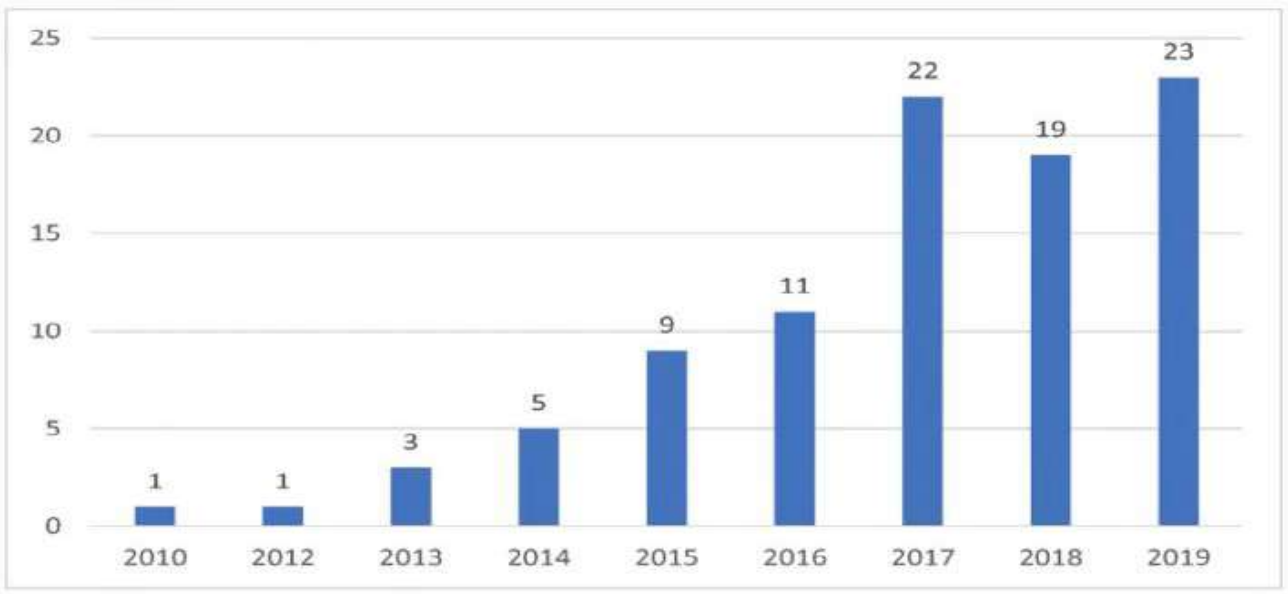

Figure 5. Publications on privacy, security and risks in smart cities: 2010-2019

From figure. 5 it is evidently clear that research community interest has immensely increased in the study of privacy, security and risk of drones in smart cities. As we know that drone technology provides a lot of advantages and benefits in our day today life but on the other hand its security issues must also be studied thoroughly to avoid any risk that may fall out from its usage. Moreover, security and privacy breaches must be addressed properly. Recording and image capturing must be done keeping in mind the privacy and confidentiality of peoples' concerns[12].

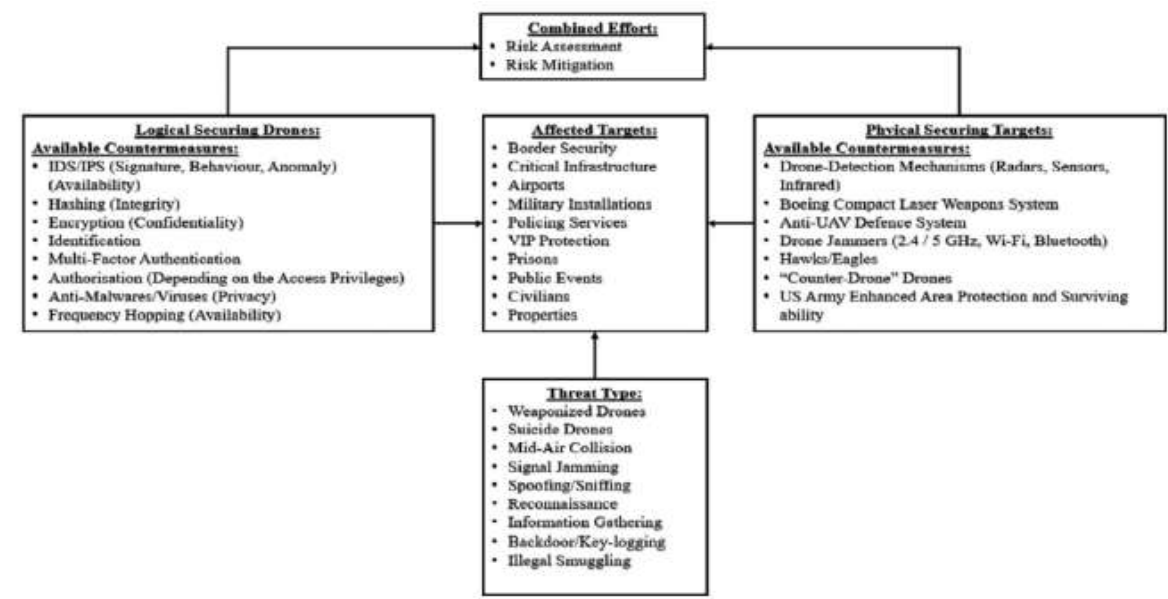

Figure 6. Drone's threat taxonomy 
Several types of risks are associated with the usage of drone especially cyber and physical attack. It is also important to note that the usage of drone must be restricted to only those areas where it is needed and should be avoided in civilian areas and properties. It is also seen widely that the owners of drone use Bluetooth technology to control their devices and use it in restricted area which creates problem for citizens and civilians. It is also reported in many literatures that drone usage also interfere in Wi-Fi connections and Bluetooth signal which raise the issue of privacy and security concerns.

However, with the advancement of technology particularly in the field of machine learning it has become possible to prevent these attacks by predicting them in advance. For example, jamming attack can be dealt with the security technique namely secure offloading which can be implemented in machine learning algorithm such as Q-learning[13][14] and DQN[15]. Other attacks such as intrusion, malware, denial of service, spoofing and traffic blockage can be realized with the help of popular machine learning algorithms namely naives bayes algorithm[16], support vector machine[17], k-NN [18] and neural networks.

Small drones are catching attention of research community due to their small size and light weight and less number of wings. Moreover, the security and privacy of individual and governments under threat due to these drones. There are several other studies which highlight common challenges and threat to individual and government agencies[19][20].

\section{Conclusion}

Concept of smart cities is catching attention across the globe and it's important as per context of emerging economies. In this paper, we discussed about the use of emerging technologies to make it possible. Al, Blockchain and Drone technologies are playing important role. Their significance and attention by researchers in exploring possibilities is shown in this paper. This paper will be very useful for researchers and engineers working in the same domain.

\section{References}

[1] T. Hariguna, U. Rahardja, Q. Aini, and Nurfaizah, "Effect of social media activities to determinants public participate intention of e-government," Procedia Comput. Sci., vol. 161, pp. 233-241, 2019, doi: 10.1016/j.procs.2019.11.119.

[2] M. Zarlis, E. P. Harahap, and L. N. Husna, "Test Appraisal System Application Based on YII Framework as Media Input Student Value Final Project and Thesis Session at Higher Education," Aptisi Trans. Technopreneursh., vol. 1, no. 1, pp. 73-81, Mar. 2019, doi: 10.34306/att.v111.31.

[3] Z. Lv, L. Qiao, A. Kumar Singh, and Q. Wang, "Al-empowered loT security for smart cities," ACM Trans. Internet Technol., vol. 21, no. 4, pp. 1-21, 2021.

[4] P. Garg, A. S. Chakravarthy, M. Mandal, P. Narang, V. Chamola, and M. Guizani, "Isdnet: Ai-enabled instance segmentation of aerial scenes for smart cities," ACM Trans. Internet Technol., vol. 21, no. 3, pp. 1-18, 2021.

[5] C. Englund, E. E. Aksoy, F. Alonso-Fernandez, M. D. Cooney, S. Pashami, and B. Åstrand, "Al perspectives in Smart Cities and Communities to enable road vehicle automation and smart traffic control," Smart Cities, vol. 4, no. 2, pp. 783-802, 2021.

[6] U. Majeed, L. U. Khan, I. Yaqoob, S. M. A. Kazmi, K. Salah, and C. S. Hong, "Blockchain for loT-based smart cities: Recent advances, requirements, and future challenges," $J$. Netw. Comput. Appl., p. 103007, 2021.

[7] L. Tan, H. Xiao, K. Yu, M. Aloqaily, and Y. Jararweh, "A blockchain-empowered crowdsourcing system for 5g-enabled smart cities," Comput. Stand. Interfaces, vol. 76, p. 103517, 2021.

[8] C. Lukita, M. Hatta, E. P. Harahap, and U. Rahardja, "Crowd funding management platform based on block chain technology using smart contracts," J. Adv. Res. Dyn. Control Syst., vol. 12, no. 2, 2020, doi: 10.5373/JARDCS/V12I2/S20201236. 
[9] P. Manju, D. Pooja, and V. Dutt, "Drones in Smart Cities," Al loT-Based Intell. Autom. Robot., pp. 205-228, 2021.

[10] N. D. Dung, "Developing transport management system for integrating drones with smart cities." Budapest University of Technology and Economics, 2021.

[11] S. Liao, J. Wu, J. Li, A. K. Bashir, and W. Yang, "Securing Collaborative Environment Monitoring in Smart Cities Using Blockchain Enabled Software-Defined Internet of Drones," IEEE Internet Things Mag., vol. 4, no. 1, pp. 12-18, 2021.

[12] L. A. Faza, P. M. Agustini, S. Maesaroh, A. C. Purnomo, and E. A. Nabila, "Motives For Purchase of Skin Care Product Users (Phenomenology Study on Women in DKI Jakarta)," ADI J. Recent Innov., vol. 3, no. 2, pp. 139-152, 2022.

[13] S. Purnama, U. Rahardja, Q. Aini, A. Khoirunisa, and R. A. Toyibah, "Approaching The Anonymous Deployment Of Blockchain-Based Fair Advertising On Vehicle Networks," in 2021 3rd International Conference on Cybernetics and Intelligent System (ICORIS), 2021, pp. 1-6.

[14] R. Widayanti, U. Rahardja, F. P. Oganda, M. Hardini, and V. T. Devana, "Students Formative Assessment Framework (Faus) Using the Blockchain," in 2021 3rd International Conference on Cybernetics and Intelligent System (ICORIS), 2021, pp. 1-6.

[15] K. El Emam, "Seven ways to evaluate the utility of synthetic data," IEEE Secur. Priv., vol. 18 , no. 4, pp. 56-59, 2020.

[16] E. Ranyal and K. Jain, "Unmanned Aerial Vehicle's Vulnerability to GPS Spoofing a Review," J. Indian Soc. Remote Sens., vol. 49, no. 3, pp. 585-591, 2021.

[17] S. Euler, H.-L. Maattanen, X. Lin, Z. Zou, M. Bergström, and J. Sedin, "Mobility support for cellular connected unmanned aerial vehicles: Performance and analysis," in 2019 IEEE Wireless Communications and Networking Conference (WCNC), 2019, pp. 1-6.

[18] R. Majeed, N. A. Abdullah, M. F. Mushtaq, and R. Kazmi, "Drone security: Issues and challenges," Parameters, vol. 2, p. 5GHz, 2021.

[19] H. P. D. Nguyen and D. D. Nguyen, "Drone application in smart cities: The general overview of security vulnerabilities and countermeasures for data communication," Dev. Futur. Internet Drones Insights, Trends Road Ahead, pp. 185-210, 2021.

[20] M. Azmi, M. S. Shihab, D. Rustiana, and D. P. Lazirkha, "The Effect Of Advertising, Sales Promotion, And Brand Image On Repurchasing Intention (Study On Shopee Users)," IAIC Trans. Sustain. Digit. Innov., vol. 3, no. 2, pp. 76-85, 2022. 